\title{
Crustal thickness in Antarctica from CHAMP gravimetry
}

\author{
M. Llubes ${ }^{\mathrm{a}, *}$, N. Florsch ${ }^{\mathrm{b}}$, B. Legresy ${ }^{\mathrm{a}}$, J.-M. Lemoine $^{\mathrm{c}}$, S. Loyer ${ }^{\mathrm{c}}$, \\ D. Crossley ${ }^{\mathrm{d}}$, F. Rémy ${ }^{\mathrm{a}}$ \\ a UMR5566/CNES/CNRS, 18 avenue Edouard Belin, 31401 Toulouse Cedex 4, France \\ b UMR Sisyphe, Département de Géophysique Appliquée, Case courrier 105, Université P. et M. Curie, 4 place Jussieu, \\ 75252 Paris Cedex 5, France \\ c Groupe de Recherche en Géodésie Spatiale, 18 avenue Edouard Belin, 31401 Toulouse Cedex 4, France \\ d Department of Earth and Atmospheric Sciences, St. Louis University, 3507 Laclede Ave., St. Louis, MO 63103, USA
}

\begin{abstract}
CHAMP, flying at an altitude of about $400 \mathrm{~km}$, is the first of a new generation of satellites dedicated to Earth gravity field observation. The high-quality data have generated new gravity field models: EIGEN-1S in 2001, and EIGEN-2S more recently. The gravitational potential is decomposed into spherical harmonic coefficients and in this study we use the free air gravity anomalies reconstituted up to degree 60 , at zero altitude. The anomalies for the Antarctic continent range from -57 to $65 \mathrm{mGal}$. We have modeled the gravity effect from the ice, the ocean and the bedrock, using a $666 \mathrm{~km}$ cut-off filter to simulate the resolution obtained by CHAMP. Computing the differences between this terrain effect and the CHAMP map provides a map of the Bouguer anomalies. Because of the dominant influence of the crust, we first used a crustal thickness model from seismology. This gives a map of the mantle Bouguer anomalies, the range of which is still large (between -255 and $216 \mathrm{mGal}$ ) indicating imperfections in the crust model. By appealing to isostasy we then imposed the condition that this mantle Bouguer anomaly should vanish and therefore solve for a new resulting crustal thickness. This gravity-based crust model gives thicknesses from 8.5 to $42.6 \mathrm{~km}$ in the zone of interest. There is a good general agreement with seismological models, but our models shows more detail, particularly in the western part of the continent. These details are in agreement with geological studies. (C) 2003 Elsevier Science B.V. All rights reserved.
\end{abstract}

Keywords: gravimetry from satellite; Antarctic; crust thickness

\section{Introduction}

Until now, the EGM96 gravity model has pro-

\footnotetext{
* Corresponding author. Tel.: +33-5-61-33-28-62; Fax: +33-5-61-25-32-05.

E-mail addresses: muriel.llubes@cnes.fr (M. Llubes), florsch@ccr.jussieu.fr (N. Florsch), benoit.legresy@cnes.fr (B. Legresy), lemoine@notos.cst.cnes.fr (J.-M. Lemoine), sylvain.loyer@cnes.fr (S. Loyer), crossley@eas.slu.edu (D. Crossley), frederique.remy@cnes.fr (F. Rémy).
}

vided the best complete global gravity field of the Earth. It is based on a compilation of all the available data [1] to derive a gravitational potential up to degree 120. This solution has already served as the basis for a global study over Antarctica [2]. Unfortunately this gravity database is not homogeneous, either in terms of quality or in terms of data distribution. Some zones are poorly sampled and required extensive interpolation, sometimes over huge areas. The launch of CHAMP therefore provides a unique opportunity to study the entire Antarctic territory with a uni- 
form, good-quality, homogeneous data set. In this study, we use the new gravity maps derived from CHAMP $[3,4]$ to estimate the crust thickness by using some simple models of the crust and mantle linked to isostasy. The results are compared to those obtained by previous methods.

\subsection{The scientific interest of Antarctica}

Antarctica extends over an area of $14 \times 10^{6}$ $\mathrm{km}^{2}$, and is quasi-totally covered by a large ice cap (about 99\%), whose thickness is up to $4800 \mathrm{~m}$, with a mean of $2200 \mathrm{~m}$. It is not, of course, an easy place for scientific studies; working conditions are marginal at best and ground-based data surveys are barely feasible. Geological studies indicate that a large chain of mountains, the Transantarctic Mountains, divides the continent into two unequal parts, the East Antarctic block and the West Antarctic block. Their geographic location is shown in Fig. 1. The eastern part is composed of old continental crust that is thick

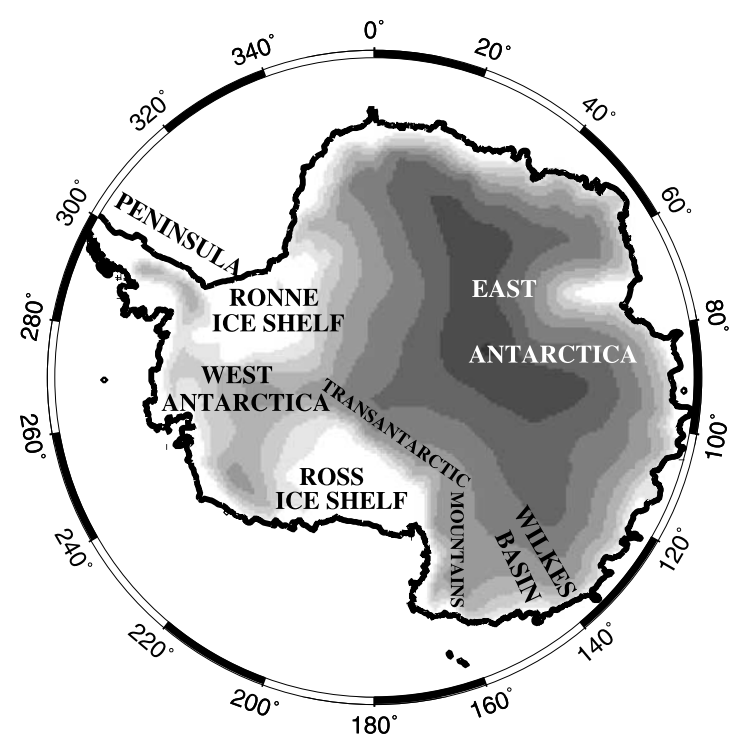

$0 \quad 500100015002000250030003500400045005000$ meters

Fig. 1. Topographic map of Antarctica with the main areas cited in the text. and relatively homogeneous. The western part results from several phases of more recent formation, and is composed of an assemblage of thinner micro-plates $[5,6]$. The peninsula forms the third independent geological entity.

Such distinct areas are only weakly apparent in the surface morphology, mainly because of the presence of ice. The geodetic ERS1 satellite provides dense coverage and a high-resolution topographic map over the globe between $82^{\circ} \mathrm{N}$ and $82^{\circ} \mathrm{S}$. The accuracy over the ice sheet is estimated to be within $1 \mathrm{~m}$ [7]. Due to the satellite inclination, however, latitudes over $82^{\circ}$ are not seen by the instrument, thus resulting in a lack of data in the polar regions. The topographic surface is used to understand the ice dynamics, and it is therefore the most important interface to monitor for the temporal evolution of the ice, and to study its relations with climate change.

Despite progress in defining the surface topography, the mass distribution underneath the surface has yet to be improved. This means not only the thickness of ice cap, but the top of the icecrust interface as well. Evidently a misunderstanding of ice thickness will transfer into errors in the crustal topography.

A study of the gravity field is of direct application to geological structures because it integrates the entire mass distribution. Ground gravity data are available, but they are mainly limited to the continental shore areas. Several airborne gravity surveys have also been successful (see [8] for example) and they could be used to study either ice thickness [9], an important parameter for glaciological models, or variations in the crust thickness ([10-12] and many others). CHAMP data are now able to provide a much more complete view of subsurface densities. At this continental scale, the ice thickness is dominated by variations in the crust-ice interface depth that generates anomalies in the gravity field.

\subsection{Gravity observations from space}

The CHAMP satellite was launched in July 2000 and one of its main tasks was to produce a global map of the Earth's gravity field. The satellite position is measured by a GPS receiver, and 
non-gravitational accelerations - such as air drag or solar radiation pressure - are corrected using an on-board accelerometer [13,14].

This new technology provides for the first time a gravity field of high precision, high spatial resolution and almost complete global coverage. Furthermore, as the data are uniformly sampled, one can also expect the accuracy to be uniform everywhere; this is especially valuable for Antarctica where the gravity coverage needs to be improved. Up to now, the gravity field of these remote areas has been poorly constrained due to the lack of data. One approach to the problem has been to combine low-degree geopotential models, based on orbit perturbations, with a topographicisostatic model [15]. Of course altimetric satellite data provide suitable geoid maps over the oceans, but continental regions do not benefit from these data. CHAMP was designed to achieve global Earth gravity field coefficients up to mediumwavelength resolution that was not possible from orbit perturbations [16,3].

During its expected 5-year mission, the satellite will progressively fall towards Earth from an altitude of $470 \mathrm{~km}$ to one of $300 \mathrm{~km}$. The altitude acts like a low-pass filter on the gravity field perturbations. By stacking all the data and waiting for the end of the mission we can expect the most detailed map within the available spatial frequency range. The first results, however, are already promising and valuable information can be recovered from the long to medium spatial range (up to $333 \mathrm{~km}$ for a half wavelength).

\section{Gravity study of Antarctica}

We combine gravity observations from CHAMP with the theoretical gravity computed from model layers. This provides us with gravity anomalies that can be interpreted in terms of a subsurface mass distribution.

\subsection{Free air anomalies from $C H A M P$}

Combining data from GPS and the STAR accelerometer permits us to recover the gravity field. We deal with Earth's gravitational potential as a sum of spherical harmonics. For CHAMP, the potential is developed up to degree $n=120$, which is the maximum resolvable degree. The wavelength corresponding to this maximum degree is $333 \mathrm{~km}$ and the formal limit of spatial resolution is thus $166 \mathrm{~km}$ (half a wavelength). As mentioned above, however, the satellite height results in a loss of sensitivity to the shorter wavelengths of the gravity field and there is significant attenuation starting at approximately $666 \mathrm{~km}$ (degree 60). The coefficients of the spherical harmonics are linearly summed to compute the gravity anomalies at a reference height - the reference ellipsoid for instance. These gravity anomalies are of course free air gravity anomalies.

In this study, we use the 'EIGEN-2S' solution that consists in a satellite-only field model derived from 6 months of CHAMP data [4]. The free air anomaly map as seen by the satellite over Antarctica, from $-90^{\circ}$ to $-65^{\circ}$ South latitude, has values between -126 and $+116 \mathrm{mGal}\left(1 \mathrm{mGal}=10^{-5}\right.$ $\left.\mathrm{m} / \mathrm{s}^{2}\right)$. Anomalies of small size, approximately $200 \mathrm{~km}$, are clearly visible, and are in principle compatible with the 120-degree truncation level discussed above. Nevertheless, one is suspicious of the reliability of these small features. The error degree variance spectrum for CHAMP (see figure in [17]) shows that beyond degree 75 the errors follow Kaula's law (an empirical relationship) and beyond this limit there is no reliable information in the satellite gravity field.

A direct comparison with the EGM96 gravitational potential confirms that CHAMP provides reliable coefficients up to degree 60 . A test on gravity anomalies differences between EIGEN-1S and EMG96 by Reigber et al. [3], shows that the CHAMP solution provides smaller RMS errors. Therefore, to be conservative, we chose to keep only degrees $0-60$ when computing the free air anomalies from EIGEN-2S [4]; this map is shown in Fig. 2a. To have an idea of the differences with another gravity field, free air anomalies from a 'satellite-only' version of EGM96 are mapped in Fig. 2b. The discrepancies span between -36 $\mathrm{mGal}$ and $45 \mathrm{mGal}$, with a standard deviation of $8.7 \mathrm{mGal}$. In the plot of Fig. 3, the curve of the difference between EIGEN-2S and EGM96 crosses the curve of the power spectrum of 

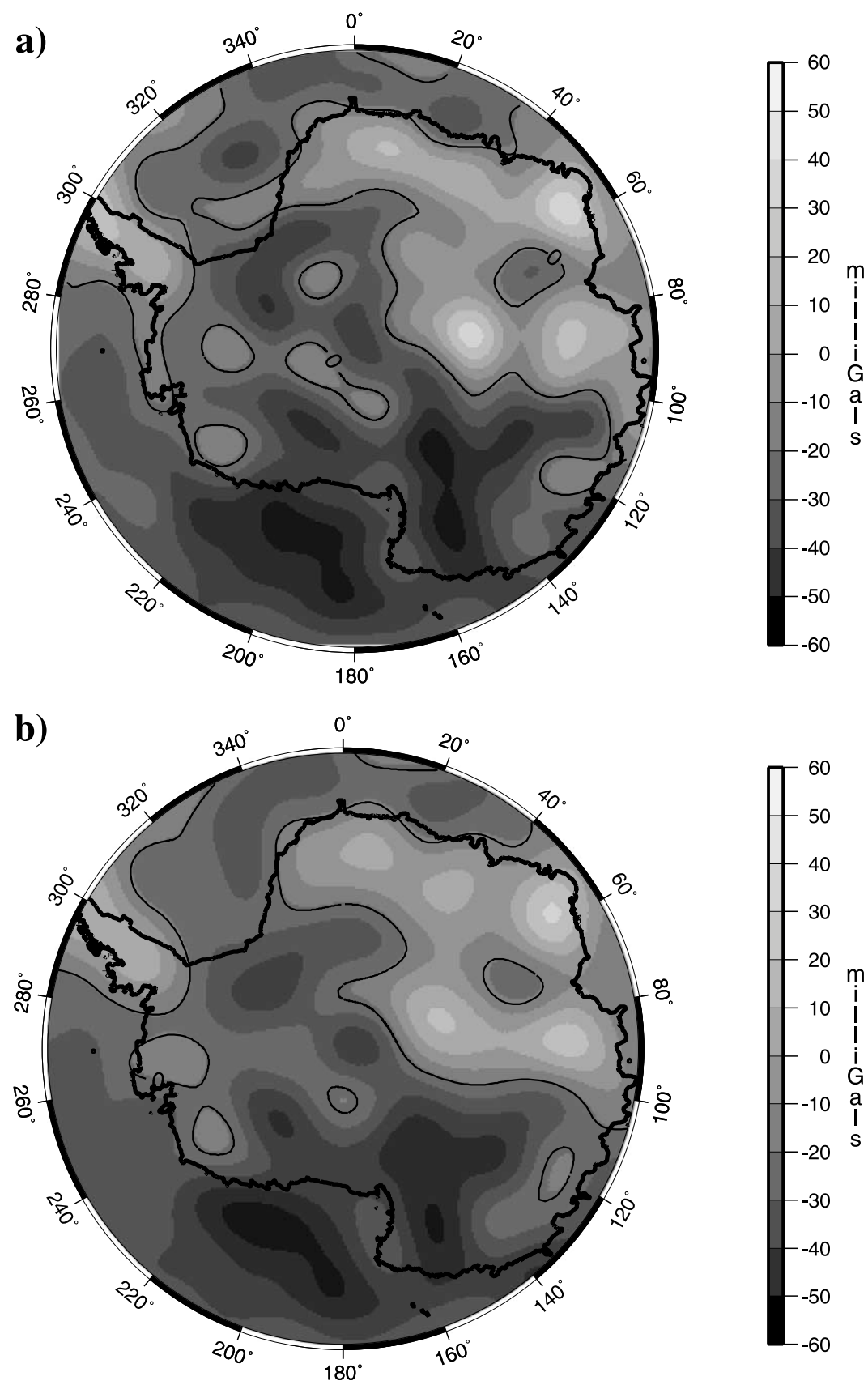

Fig. 2. (a) Free air anomalies from EIGEN-2S, with a downward continuation to zero altitude. (b) Free air anomalies from a satellite-only part of EGM96 (EGM96-S). Units are mGal.

EIGEN-2S around degree 62. It can be considered therefore that above degree 62 the error of EIGEN-2S is greater than the geopotential signal. In Table 1, the mean cumulative errors of
EIGEN-2S computed at degrees 10, 30, 50 and 70 are listed. Truncating the harmonics series at degree 60 leads to an error of about $3 \mathrm{mGal}$ in the gravity anomalies. 


\section{Geoid Amplitude per Degree}

(m)

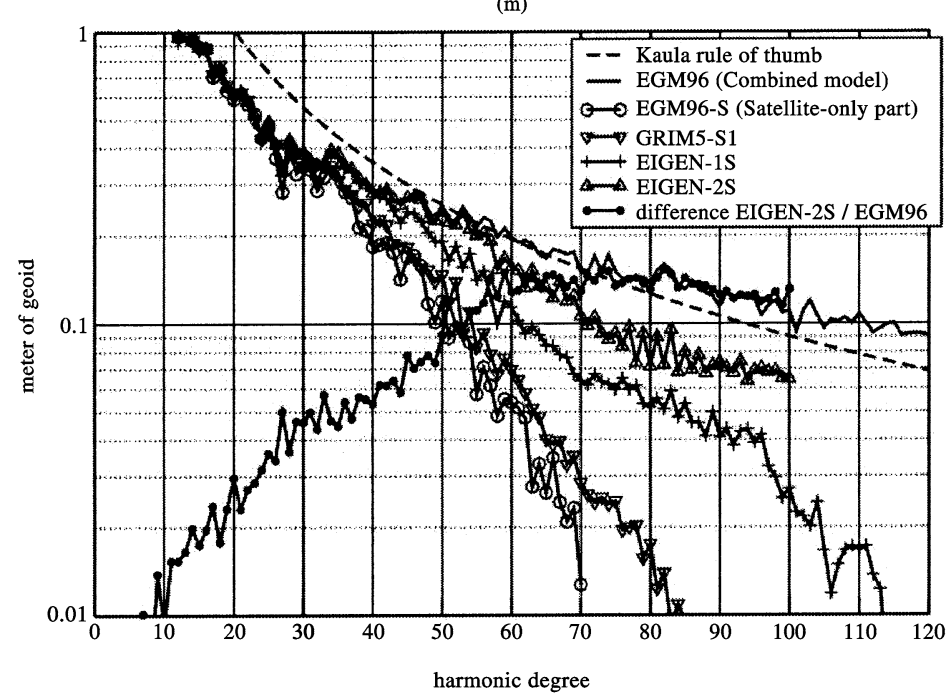

Fig. 3. Signal/error amplitudes per degree in terms of geoid heights for several gravity models, and differences between EIGEN2S and EGM96.

We now review all the variables that can produce changes in the Earth's gravity field, and estimate their accuracy in terms of gravity. We then compare the computed anomalies with those derived from the CHAMP data.

\subsection{Parameters of the gravity model}

The main parameters required to model the gravity effect of the Antarctic mass distribution are the thickness of the ice sheet, the thickness of sea water, the topography and thickness of the crust, and the respective densities of each of these layers.

1. We chose the BEDMAP ice thickness model as

Table 1

Mean cumulative errors for the gravity anomalies from EIGEN-2S

\begin{tabular}{ll}
\hline Degree & Mean error $(\mathrm{mGal})$ \\
\hline 10 & $1 \times 10^{-3}$ \\
30 & 0.11 \\
50 & 1.48 \\
70 & 4.88 \\
\hline
\end{tabular}

our reference [9] as it is generally recognized to be the best available compilation. It is based on measurements taken over the past 50 years and reduced to a grid with a spatial resolution of $5 \mathrm{~km}$. The authors estimate that the RMS error of the grid is about $150 \mathrm{~m}(8 \%$ of the mean ice thickness), but the non-homogeneous data distribution does not result in good precision everywhere over the polar cap. There are as yet wide areas not covered in the model.

2. The thickness of sea water is mainly the depth of the open ocean, but water also exists underneath ice platforms clinging to the continent, i.e. the floating ice shelves. These are areas where the bathymetry is poorly known, and where it can play a role for the local ocean circulation or for the tides. In our study, we used the Terrainbase model [18]. This is not a critical choice since we will focus on the Antarctic continent when interpreting the results. This model has been computed from the wellknown ETOPO5 [19] and it assimilates more high-quality source data in order to reduce problems in some areas. Unfortunately, no improvement in the topography of Antarctica 
was incorporated in the newest release. For example, there is no negative topography under the ice shelves as we may expect. This will be apparent in the final gravity anomaly map.

3. To estimate the bedrock topography, it suffices to subtract the ice thickness from the surface topography; so for this purpose BEDMAP still provides the current best map [9]. The accuracy of this bedrock topography is of course related to the accuracy of the ice thickness; for our purpose we need to obtain a reliable depth to the ice-bedrock interface.

4. Several Earth crust models can be chosen from those provided by seismological data. A widely used model is CRUST2.0 [20], given on a $2 \times 2$ degree grid and composed of $360 \mathrm{key} 1 \mathrm{D}$ profiles. To compute the effect of the crust on gravity, we used the 3SMAC [21], a model based on inverting seismic wave velocities. Hence, CRUST2.0 is used to test the discrepancies between the two seismological models. We found a mean difference of $0.27 \mathrm{~km}$ between them, and an RMS difference of $4 \mathrm{~km}$ that can be taken as a first estimate of the model accuracy, realizing in practice that the maximum discrepancy can reach $10 \mathrm{~km}$. If this seems a high value, we recall that neither of the above models is optimized for the Antarctic region - they are global models.

\subsection{Method}

In our computation, we can use either the crustal thickness or Moho depth. Generally, both are provided in the models. Because the bedrock topography is referenced to the ellipsoid, thanks to BEDMAP, it is unimportant whether we choose one or the other. The aim is to compute the spatial gravity contributions from all of the previous layers - the ice cap, the ocean and the crust. This will be the 'terrain gravity effect'. Usually, it is computed with respect to the reference ellipsoid, but it can be evaluated at any desired altitude.

Because CHAMP provides free air anomalies from an altitude of $400 \mathrm{~km}$, it is necessary to continue the data downward to the ellipsoid (rig- orously, to an altitude of $4 \mathrm{~km}$, just above the highest relief), by using the spherical harmonic expansion limited to degree 60 . This height, even when added to the crustal thickness, is 10 or 20 times smaller than the $666 \mathrm{~km}$ wavelength which limits the anomaly accessible spectrum. Hence, the anomalies induced by the mass distribution can be computed by using a simple Bouguer's formula, that is:

$\Delta g=2 \pi G \sum_{k} \rho_{k} t_{k}$

where $\rho_{k}$ and $t_{k}$ are the density and thickness of the $k$ th layer. Using this formula in our context, instead of a more sophisticated method (as used in [2]) leads to a maximum error of $5 \%$. The terrain gravity effect, due to the mass distribution around and beneath the surface, is then computed in a manner that simulates the CHAMP altitude effect, effectively a low-pass filter. Most of the terrain grids have a resolution greater than that of the satellite data, so since the CHAMP map is comprised of degrees up to 60 , we chose to apply a $666 \mathrm{~km}$ wavelength low-pass filter to our terrain gravity model.

We use constant density values in each layer: $917 \mathrm{~kg} / \mathrm{m}^{3}$ for the ice, 1028 for sea water, 2800 for the crust, and 3300 for the mantle. To compensate for the vertical density variation due to snow accumulation over the ice cap, we removed $30 \mathrm{~m}$ from the ice thickness. In the final discussion, we return to the influence of these density choices on gravity variations.

Usually, the comparison between terrain effect and free air anomalies shows coherent features, up to about $500 \mathrm{~km}$ wavelength, beyond which the topographic effect is counterbalanced by variations in the crust thickness. The bottom limit of the crust, the Moho, is assumed to vary in depth to isostatically compensate the topography. As our maps are limited to wavelengths larger than $666 \mathrm{~km}$, we can assume that all surface variations are compensated. This means first that no correlation is expected between topography and free air anomalies, and secondly, when comparing our model to CHAMP free air anomalies (CFAA), one must also use a crust thickness model. In the computation, the bottom of the 
mantle layer is limited to a constant depth, whose choice is of low importance because the mean mantle thickness value is removed.

\subsection{Gravity anomalies and crustal thickness}

\subsubsection{Construction of gravity effects and sensitivity}

First, we computed a simple terrain gravity effect (STGE) considering only the ice, the ocean and the bedrock topography. This effect, plotted in Fig. 4a, varies between -270 and $365 \mathrm{mGal}$. Second, we computed a more complete terrain gravity effect (CTGE) that also includes the crust thickness variations (Fig. 4b). The amplitudes of CTGE are between -206 and $203 \mathrm{mGal}$. This is slightly weaker than STGE, but both terrain effects are four or five times larger than the CHAMP anomalies.

The STGE is dominated by bedrock topography; moreover, the correlation coefficient between STGE and CFAA is only 0.2. In a crust that is isostatically compensated, this correlation coefficient should be zero because we should have removed uncompensated wavelengths by the filtering process. Introducing lateral density variations in the model is one way to explain this persistent low correlation at wavelengths above $666 \mathrm{~km}$. If one compares CFAA and CTGE, the correlation coefficient is reduced to 0.08 , meaning that the model corresponds poorly to observations. We infer that this low correlation must be a consequence of an incorrect crustal thickness in the model. Hence, we propose an alternative method for finding the crustal variations, based on CHAMP gravity maps.

We estimate separately the individual contributions that can be distinguished in the model, for example there is a maximum effect of $145 \mathrm{mGal}$ due to the ice cap and a $234 \mathrm{mGal}$ contribution due to the ocean water. It is not, of course, interesting to estimate the total effect of the crust because it would dominate the other effects - only its lateral variation plays a role. In fact, only the variations in the ice-crust and crust-mantle interface topographies are relevant, and also the estimate of their errors. For example we find that a $100 \mathrm{~m}$ error in the vertical position of ice-crust interface leads to a variation of $8 \mathrm{mGal}$ in our gravity model.

\subsubsection{Bouguer anomalies}

The traditional approach consists in the computation of the difference between observations and model: $\Delta g_{\mathrm{SBA}}=\mathrm{CFFA}-\mathrm{STGE}$, referred to as the simple Bouguer anomaly (SBA), and $\Delta g_{\mathrm{MBA}}=\mathrm{CFFA}-\mathrm{CTGE}$, referred to as the mantle Bouguer anomaly (MBA).

They are plotted as Fig. 5a and b, respectively. As expected, the SBA, which does not take into account the Moho topography, is strongly correlated with the model because the topography of the crust-mantle interface is not included in the computation. These anomalies are positive over the ocean area and negative over the continent. There is a notable difference between the East Antarctic, where values can be very negative, down to $-300 \mathrm{mGal}$, and the West Antarctic part where the values are less negative. This is consistent with a thicker crust in the east, forming a compact block, and a thinner crust in the west, formed by the aggregation of several micro-plates. The Ronne Ice Shelf and Ross Ice Shelf are both visible, with anomalies around $-30 \mathrm{mGal}$. Recall that the Terrainbase model does not consider ocean water under the platform of ice.

The MBA shows values between $-255 \mathrm{mGal}$ and $216 \mathrm{mGal}$, slightly less than the SBA in magnitude. The negative values are interpreted as a mass deficit that can be caused by a lower density - due to the presence of sediments, for instance while the positive values result from an excess of mass - associated with a crust thinner than the model in use.

\subsubsection{Crust thickness estimation}

Assuming that the MBA is entirely due to crustal thickness variations, it is possible to compute the crustal thickness by simply inverting Eq. 1 . This provides spatial variations of the Moho depth alone, so this must be vertically adjusted to estimate absolute values. We do this using an average value obtained from seismological data in Antarctica. The final crustal thickness is mapped in Fig. 6. The range is between $8.5 \mathrm{~km}$ and 42.6 $\mathrm{km}$, which is slightly less than the crustal varia- 

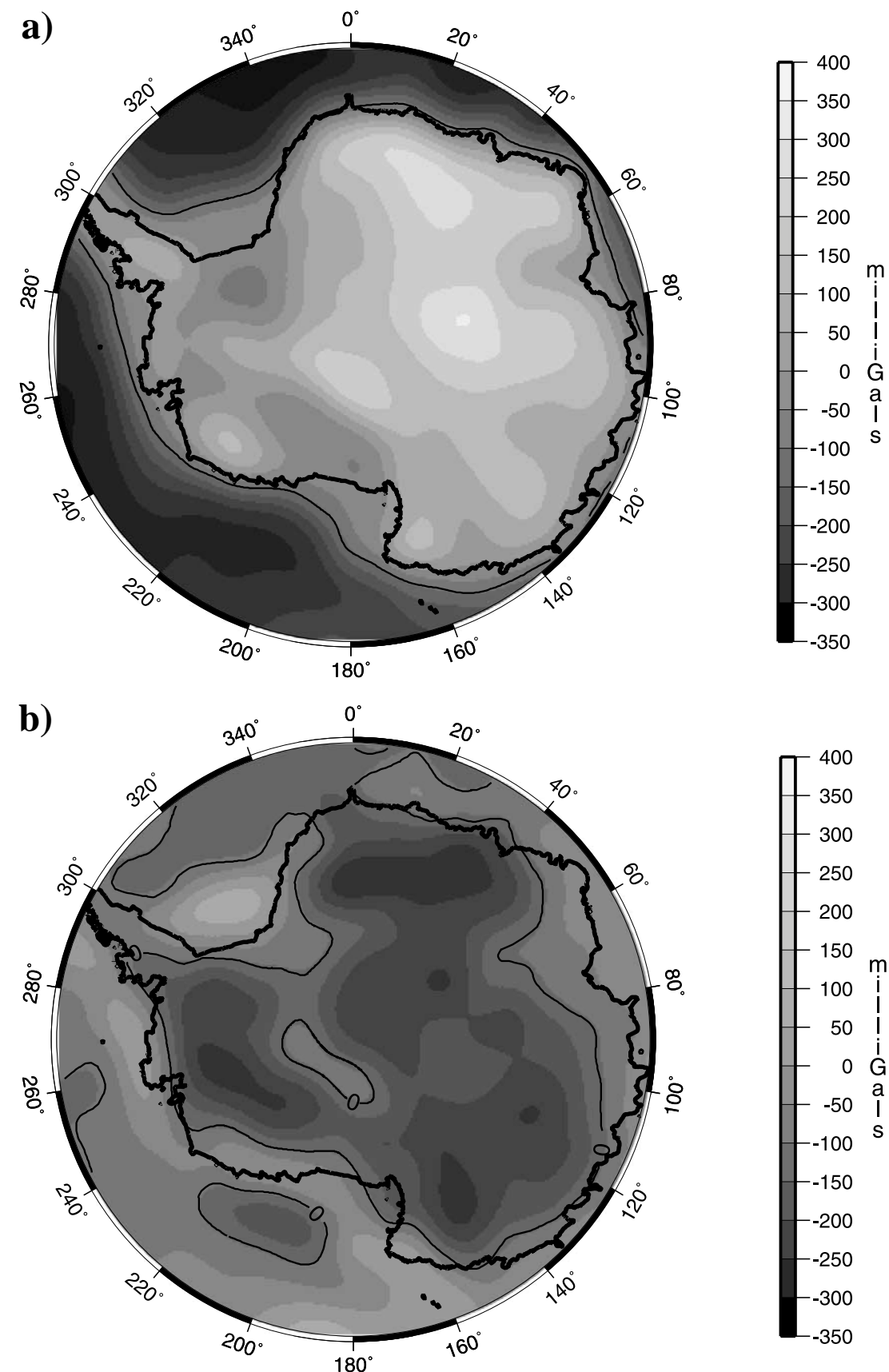

Fig. 4. (a) Terrain gravity effect (mGal) predicted from ice thickness (BEDMAP), ocean water depth (Terrainbase) and bedrock topography (BEDMAP), with a low-pass filter of $666 \mathrm{~km}$; this is the simple terrain gravity effect (STGE). (b) Same as panel a but using crust thickness from 3SMAC seismological model; this is the complete terrain gravity effect (CTGE). 

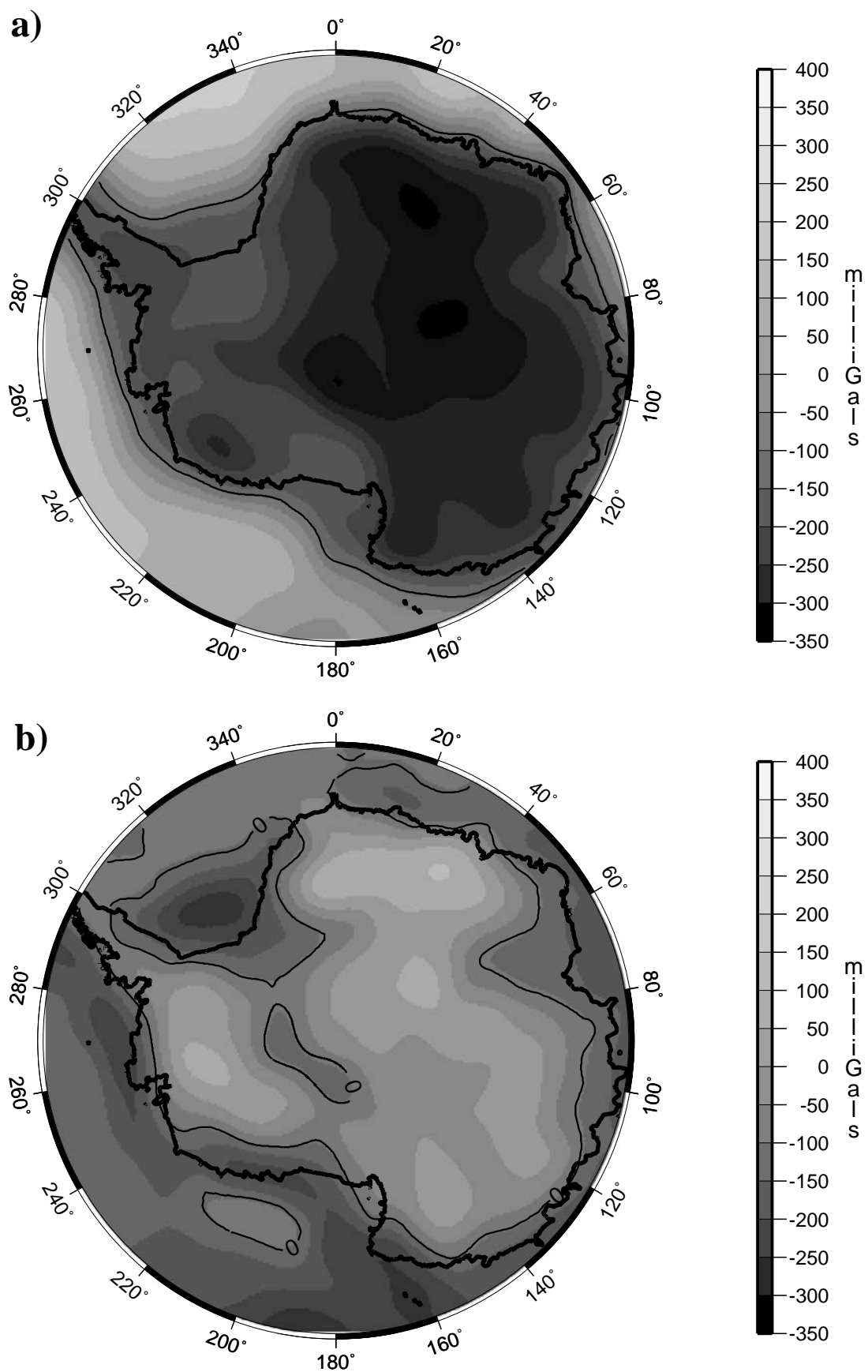

Fig. 5. (a) Simple Bouguer anomalies (mGal), computed by the difference between CHAMP free air anomalies and the STGE. (b) Mantle Bouguer anomalies (mGal), computed by the difference between CHAMP free air anomalies and the CTGE. 

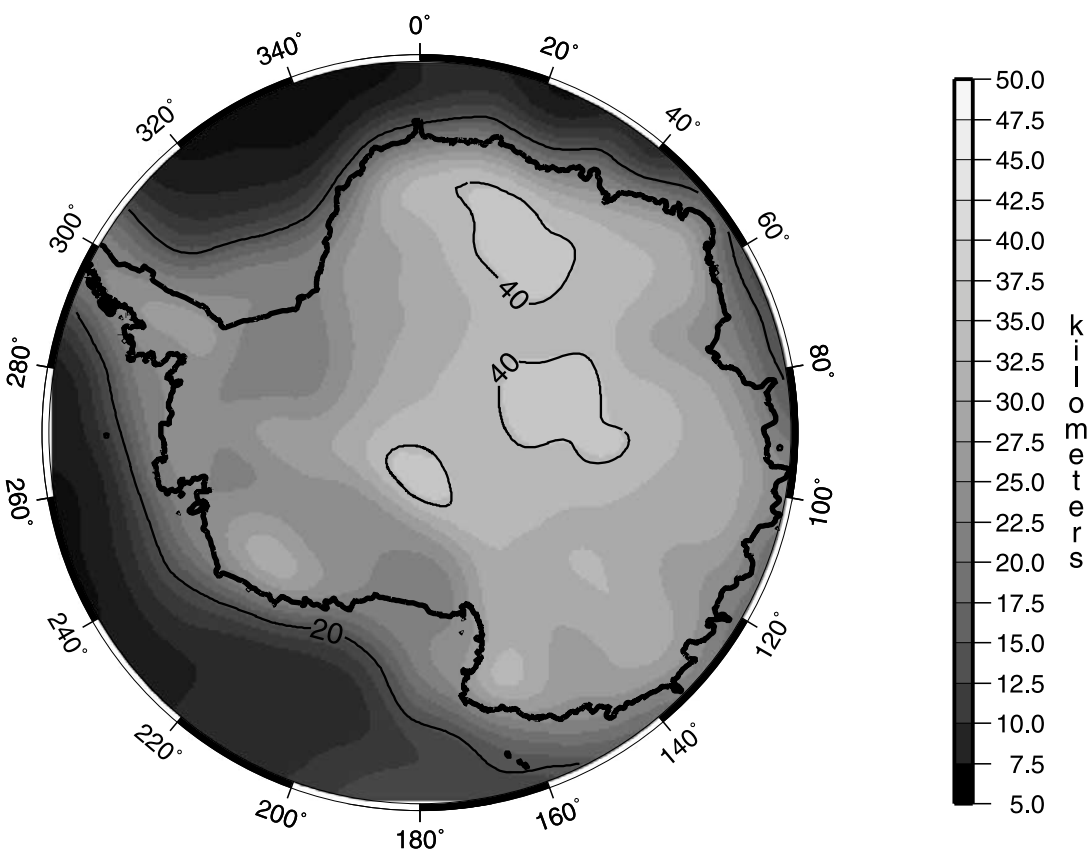

Fig. 6. Crust thickness variations (m) estimated from CHAMP Bouguer anomalies (see text for description).
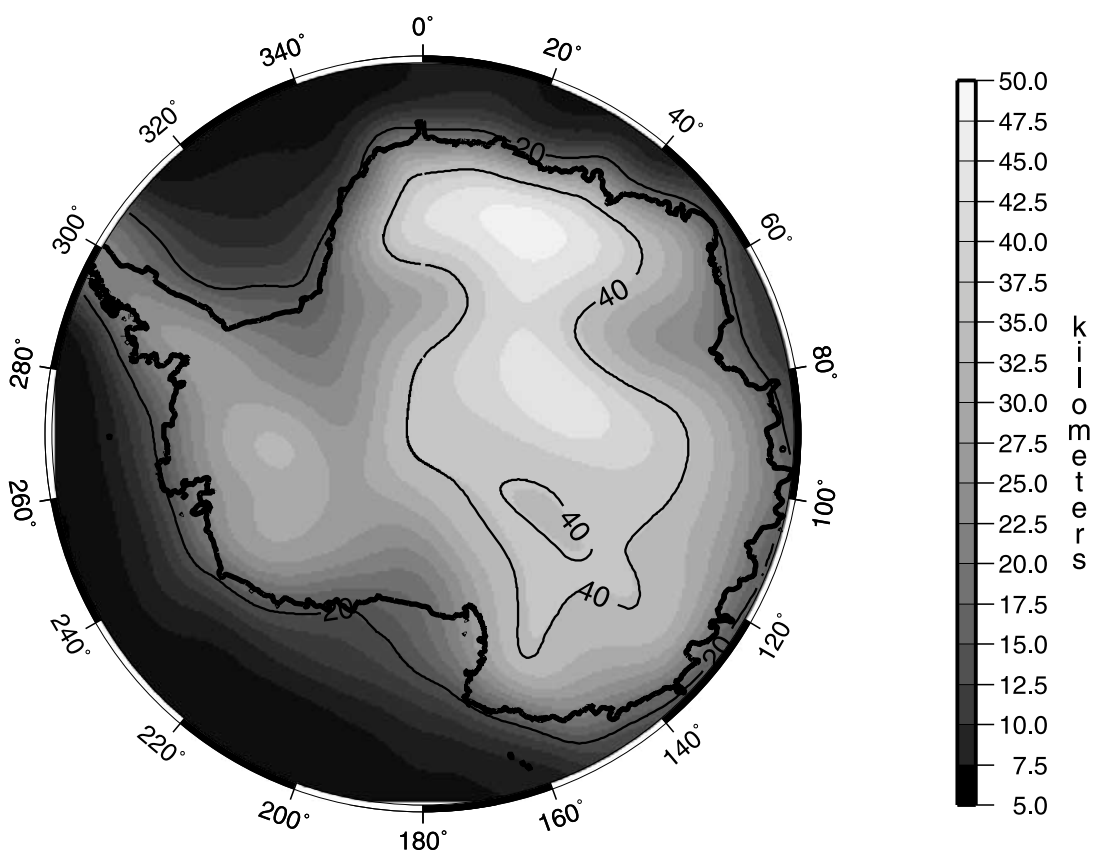

Fig. 7. Crust thickness variations (m) according to the 3SMAC model. 
tions from the 3SMAC model [21], which shows thicknesses between $7.3 \mathrm{~km}$ and $49.2 \mathrm{~km}$. Models from seismology are based on the inversion of seismic data using raytracing. One possible limitation of the 3SMAC model is the need for at least one ray in each cellular grid. Any lack of data could lead, as in this situation, to an overestimate of the thickness variations, apparent in the 3SMAC model. Crustal thicknesses from this model are plotted in Fig. 7. It is also clear that models from seismology have a lower resolution than those from gravimetry [22], due primarily to the lack of spatial distribution of the receivers.

The estimated crust thickness from CHAMP nevertheless reveals features close to 3SMAC results in the western part of the continent, with a large area showing a thicker crust in the center and in the north. In the eastern part of Antarctica, the 3SMAC results yield a homogeneous continental crust, thinning slowly towards the ocean margin. By comparison our model shows several smaller structures, in better agreement with geological data for the region. The two big ice shelves seem to be overlying a thin lower crust. This may partly be due to the omission of low-density ocean water under the ice, but it may also reflect the actual situation.

\section{Discussion}

\subsection{Ice thickness}

From the glaciologist's point of view, there is a benefit that will be provided by the new CHAMP data - the ice thickness over Antarctica. This parameter is well determined for some areas where there are borehole sites, seismic profiles, airborne gravimetry or radio echo sounding. Thanks to altimetry, the surface topography is mapped with a high level of precision [7]. But we have been lacking a systematic data set for finding the underneath ice-crust interface depth. Present thicknesses all come from dedicated special studies, confined to spatial areas of interest. Due to the access facilities, they are mainly located around the continental margins, but there are also some profiles penetrating into the central re- gions (see [9] for the distribution of the data). In some areas, the accuracy of the ice thickness measurements is very good: for instance in Terre Adelie. Nevertheless the ice thickness has been interpolated over huge regions where the accuracy decreases dramatically - sometimes no better than $\pm 500 \mathrm{~m}$. Recall that a mismodeling of $100 \mathrm{~m}$ in the ice-crust interface generates about $8 \mathrm{mGal}$ in the gravity anomalies. Compared to the values currently encountered in the anomaly maps, even a $500 \mathrm{~m}$ error would not be easily detected. And except if another source of information is used, it would be impossible to decide if it is generated by ice or crust. On the other hand, a wrong assignment of $40 \mathrm{mGal}$ to the crust thickness would lead to a $2 \mathrm{~km}$ misinterpretation on the position of the crust-mantle interface.

\subsection{Crustal thickness as seen by gravimetry}

Although we have assumed a constant density within each layer of the model, we show quantitatively that the discrepancies observed between CFAA and CTGE result from poor knowledge of the crustal thickness. The crustal effect dominates the other parts of the model, so that it is legitimate to transform the gravity map into one that shows crustal thickness variations. Satellitebased gravimetry provides a complete coverage of the Antarctic area, with uniform precision and accuracy, and without the survey inconsistencies and other difficulties that ground-based field surveys must face.

The discrepancy between the 3SMAC crust thickness [21] and the one we computed from the gravity is at the level of $4 \mathrm{~km}$ RMS. This is slightly higher if one uses the CRUST2.0 model [20] instead of 3SMAC, giving an RMS of $4.5 \mathrm{~km}$ and with a maximum discrepancy of $11 \mathrm{~km}$. Similar values are found when the two seismic models are inter-compared. The generally good agreement with the crustal models from seismology tends to validate our results. The actual resolution is limited to degree 60 (333 km half-wavelength), but further improvement is expected with more data. The CHAMP mission will continue until 2005 and the altitude of the satellite decreases about $1.5 \mathrm{~km}$ each month. The lower the satellite 
altitude, the better the resolution; the data stacking will also improve the precision proportionally as the square root of the time elapsed since the launching.

Satellite gravimetry is thus a natural and efficient new tool for studies of Antarctica. Global crustal models based on seismological data need dense station coverage in order to resolve details of the Earth's interior - a minimum of one source-receiver ray per cellular grid. In Antarctica, ground-based data are obviously less numerous, leading to lower resolution. We find that models 3SMAC or CRUST2.0 cannot see some of the crustal details in West Antarctica that we are able to resolve from inversion of the CHAMP gravity field. Blocks of Marie Byrd Land, Ellsworth-Whitmore Mountains and Antarctic Peninsula as described in [5] can be distinguished by CHAMP (Fig. 6), but not by the seismological models (Fig. 7).

\subsection{Effect of density variations}

We return to the possible role of the densities of the layers in our models. As far as ice and sea water are concerned, the lateral density variations are confined to a narrow range of realistic values, and these can be neglected compared to other contributions. For crustal rocks, samples or seismic studies show a mean density of $2400 \mathrm{~kg} / \mathrm{m}^{3}$ for sediments and $2900 \mathrm{~kg} / \mathrm{m}^{3}$ for basalts, gneiss, etc. (see $[6,11,23]$ ). Since the Antarctic crust is mainly composed of basement rocks, our choice of $2800 \mathrm{~kg} / \mathrm{m}^{3}$ is realistic and in agreement with the seismology [24]. But inside the continent, density variations lead to a significant correlation between the actual crustal density and the crust thickness when attempting to retrieve the latter. A reliable choice of density values is obviously important, even for geodesy studies [25]. To constrain the variations of density, inverse theory can be applied to gravity anomalies in a joint solution for seismic travel times [26].

Here, we present an attempt to estimate the effective density variations. We follow the same principle as for the estimation of the crustal thickness, i.e. a density value for the crust is computed by assuming that the MBAs are entirely due to
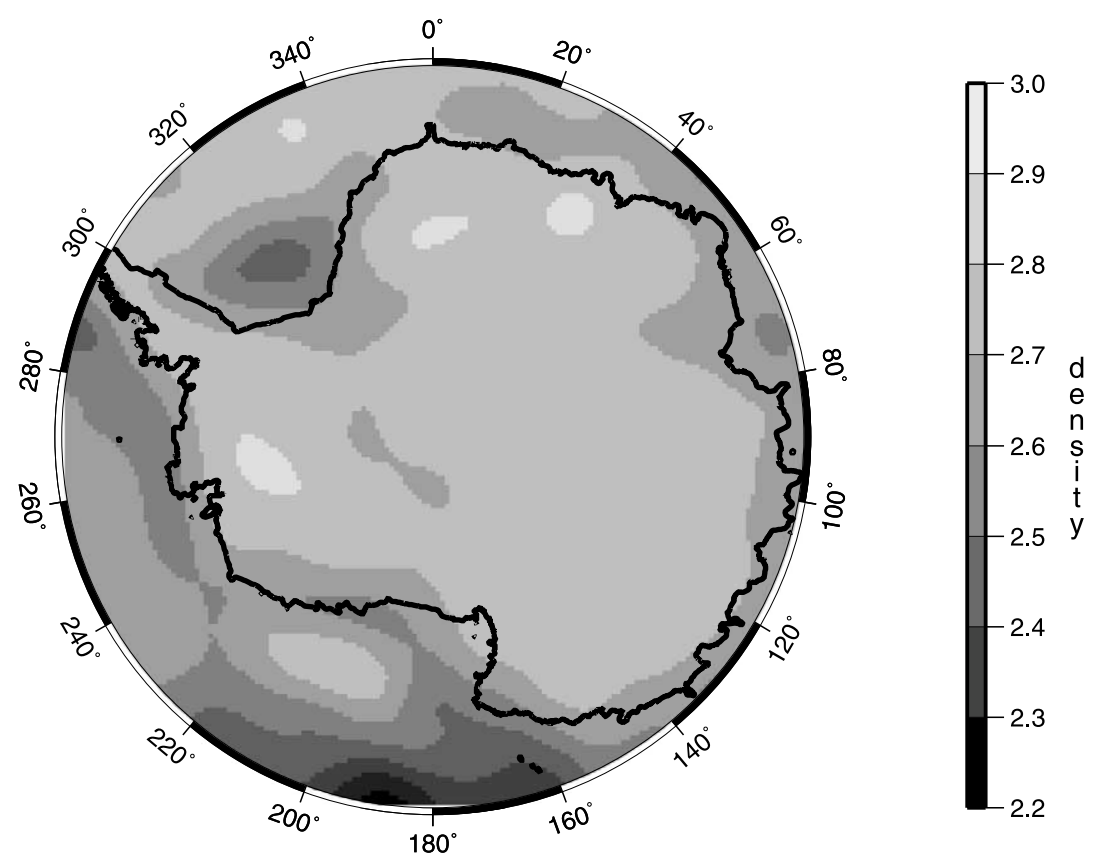

Fig. 8. Map of crustal densities computed from the free air anomalies of EIGEN-2S and from the terrain effect model using crust thicknesses given by 3SMAC (see text). 
density variations. The 3SMAC crust model serves as an input in the calculation. The aim is not to obtain a fully realistic interpretation, but to estimate the possible effect of a poor density assumption and to evaluate the robustness of our previous models.

When we plot the map of the computed density (see Fig. 8), a similarity appears with the MBAs. Except in a few restricted areas, almost the whole of the Antarctic continent has the same value, between 2800 and $2900 \mathrm{~kg} / \mathrm{m}^{3}$. This confirms that our previous choice of $2800 \mathrm{~kg} / \mathrm{m}^{3}$ is suitable. On the other hand, the density does not need to change a lot to produce gravity anomalies. Recall that the low 0.2 correlation coefficient we found between CFAA and STGE is likely to result from sources other than those due to isostatic compensation, and may also come from spatial density variations. Around the borders of the continent, the density decreases by about $100 \mathrm{~kg} / \mathrm{m}^{3}$. This may reflect the presence of sediments that are already recognized in geological studies. In return, there is no correlation between density and crustal thickness, although there is an equivalence law (the usual correlation) between these two parameters. A thinner crust, for example, generates a mass excess that can also be interpreted as an increase of the density. It seems that some features are better interpreted by one assumption than the other, and that a sort of spatial de-correlation is possible. However, geological information is essential to confirm the interpretation of features that come from gravity data, and to help separate the two effects when ambiguities persist.

We test a simple density variation model to improve the CTGE computation. The area is divided into two parts: the continental homogeneous one, which has a density of $2840 \mathrm{~kg} / \mathrm{m}^{3}$, and the remainder, which has one of $2695 \mathrm{~kg} / \mathrm{m}^{3}$. The Terrainbase model [18] is used to separate these two zones, and the chosen densities are found by computing the mean density from our previous density map over each area. This simple model shows a large influence on CTGE, because it leads to a correlation coefficient equal to 0.25 - instead of the 0.08 previous value - when we replace the constant $2800 \mathrm{~kg} / \mathrm{m}^{3}$ density by this zonal density.

\subsection{Focus on local geological features}

Now, it is possible to interpret our crust thickness map. We chose to investigate at the Wilkes Basin zone because it is a large basin, marked in the bedrock topography and parallel to the main geological feature, the Transantarctic Mountains. Previous authors have proposed a flexural uplift scenario for the formation of the mountains [23], with a resulting low over the flexure that is Wilkes Basin. Geological interpretation suggests an extended crust in this region, and previous studies clearly detected a thinning of the crust associated with the topographic depression [11]. Our model of crustal thickness indicates a thinning of the crust in this zone over an area 200-600 km wide. We therefore compute, around the latitude of $-74^{\circ} \mathrm{S}$, the mean crust thickness over three different areas. The first, from $126^{\circ} \mathrm{E}$ to $139^{\circ} \mathrm{E}$, has a thickness of $37.5 \mathrm{~km}$. The central zone, corresponding to Wilkes Basin between $144^{\circ} \mathrm{E}$ and $152^{\circ} \mathrm{E}$, is thinner, only $35.6 \mathrm{~km}$. And the third part, near $155^{\circ} \mathrm{E}$ and corresponding to the Transantarctic Mountains, again has a $37.5 \mathrm{~km}$ thickness. A previous joint gravity/magnetic study of the region gives respectively $34-37 \mathrm{~km}, 31-34 \mathrm{~km}$ and $34-37 \mathrm{~km}$ for each of these regions [11]. Crustal thickness variations derived from CHAMP are therefore a little weaker, but still apparent. Computations with the 3SMAC model give a constant value of $40 \mathrm{~km}$ over the whole zone, because of the lower resolution of the seismological models. The Wilkes basin furrow can be seen on our crust map as a slightly thinner feature.

Of course, other potential sources may generate gravity anomalies. They could come from within or beneath the crust, like variations in the mantle density. But given the uncertainties on the classical parameters - the ice-crust and crust-mantle interface, the spatial variations of the density of the crust - and also on the CHAMP gravity map, it is a delicate issue to involve the presence of deeper structures.

\section{Conclusion}

The CHAMP mission opens real opportunities 
for gravimetric studies of remote regions. When surface or airborne data are lacking, it can provide an excellent complement, better than any ground spatial interpolation scheme. This can be seen as an inter-validation of the gravity maps over averaged cells that take into account the lower resolution of CHAMP, due to its altitude. It has been shown in this study that satellite gravimetry is able to see features up to a spatial resolution of $333 \mathrm{~km}$.

Because of the importance of Moho depth variations on the anomaly map, and particularly due to the errors, the modeling of terrain gravity effect does not allow us to extract precise information about ice thickness. The model is seriously affected by errors in the depth of the ice-crust interface. This plays an important role in glaciology, where it is an input to the glacier models, permitting the evaluation of ice flow, friction at the base of the ice, and the overall evolution of the ice cap. This study will be possible with CHAMP for the lower degrees only, and also with the GRACE mission because the crust does not have temporal variations during the 5 years of the satellite's life [27]. GRACE is dedicated primarily to the study of geophysical fluids. For studies of the static gravity field, GOCE will be launched in a few years, and it is expected to improve the precision and the resolution by at least one order of magnitude. Nonetheless, the ice/crust spatial variations will still be masked by inaccuracies in the crustal model. To obtain such accurate information, we may have to wait for the Icesat satellite just launched in January 2003 [28], and future missions.

In this study, we use the map of free air anomalies derived from CHAMP data, and we compute the sum of gravity effects generated by the ice cap, sea water and crust. The Bouguer anomalies are strong, even if Moho depth variations are taken into account in the model. There is still a weak 0.2 correlation coefficient between the simple terrain effect - without crust thickness variations - and CHAMP free air anomalies. Because all maps are $666 \mathrm{~km}$ low-pass filtered, this correlation implies phenomena other than isostatic compensation. Lateral density variations may be one explanation.
The correlation coefficient between the complete terrain effect and the CHAMP free air anomalies is only 0.08 , meaning that our 'best' model is far from real observations. This is due to a poor modeling of the crustal thickness. Compared to our estimate found by an inversion assuming that the Bouguer anomaly is due to crustal thickness variations, the seismological model presents stronger variations and a coarser resolution.

It has thus been shown here that CHAMP provides good-quality data for Antarctica, with a complete and dense coverage that is validated for studies of mass distribution. The dominant signal comes from the crust, and the estimate of crustal thickness variations is consistent with other studies and geological data. Seismological models could benefit from these gravimetric observations in other regions where data are lacking, for example using a joint seismological-gravimetric data inversion process. Further improvements to the CHAMP gravity field, when more observations will be available, and when the satellite altitude will be lower, are anticipated.

\section{Acknowledgements}

We thank an anonymous referee for his helpful comments on the manuscript.[AC]

\section{References}

[1] F.G. Lemoine, S.C. Kenyon, J.K. Factor, R.G. Trimmer, N.K. Pavlis, D.S. Chinn, C.M. Cox, S.M. Klosko, S.B. Luthcke, M.H. Torrence, Y.M. Wang, R.G. Williamson, E.C. Pavlis, R.H. Rapp, T.R. Olson, The development of the joint NASA GSFC and the National Imagery and Mapping Agency (NIMA) geopotential model EGM96, NASA Technical paper NASA/TP1998-206861, Goddard Space Flight Center, Greenbelt, MD, 1998.

[2] R.R.B. von Frese, L. Tan, J.W. Kim, C.R. Bentley, Antarctic crustal modeling from the spectral correlation of free-air gravity anomalies with the terrain, J. Geophys. Res. 104 (B11) (1999) 25275-25296.

[3] Ch. Reigber, G. Balmino, P. Schwintzer, R. Biancale, A. Bode, J.-M. Lemoine, R. Koenig, S. Loyer, H. Neumayer, J.-C. Marty, F. Barthelmes, F. Perosanz, S. Y. Zhu, A high quality global gravity field model from CHAMP 
GPS tracking data and accelerometry (EIGEN-1S), Geophys. Res. Lett. 29 (2002) 10.1029/2002GL015064.

[4] Ch. Reigber, P. Schwintzer P., K.-H. Neumayer, F. Barthelmes, R. König, Ch. Förste, G. Balmino, R. Biancale, J.-M. Lemoine, S. Loyer, S. Bruisma, F. Perosanz, T. Fayard, The CHAMP-only Earth Gravity Field Model EIGEN-2, Adv. Space Res. (2003) in press.

[5] J.B. Anderson, Antarctic Marine Geology, Cambridge University Press, Cambridge, 1999, 289 pp.

[6] M. Studinger, H. Miller, Crustal structure of the FilchnerRonne shelf and coasts land. Antarctica, from gravity and magnetic data: implication for the breakup of Gondwana, J. Geophys. Res. 104 (B9) (1999) 20379-20394.

[7] F. Rémy, P. Shaeffer, B. Legresy, Ice flow physical processes derived from the ERS-1 high resolution map of the Antarctica and Greenland ice sheets, Geophys. J. Int. 139 (1999) 645-656.

[8] R.E. Bell, V.A. Childers, R.A. Arko, D.D. Blankenship, J.M. Brozena, Airborne gravity and precise positioning for geologic applications, J. Geophys. Res 104 (B7) (1999) 15281-15292.

[9] M.B. Lythe, D.G. Vaughan, the BEDMAP Consortium, BEDMAP: A new ice thickness and subglacial topographic model of Antarctica, J. Geophys. Res. 106 (B6) (2001) 11335-11351.

[10] A. Ikami, K. Ito, Crustal structure in the Mizuho plateau, east Antarctica, by a two-dimensional ray approximation, J. Geodyn. 6 (1986) 271-283.

[11] F. Ferraccioli, F. Coren, E. Bozzo, C. Zanolla, S. Gandolfi, I. Tabacco, M. Frezzotti, Rifted (?) crust at the East Antarctic Craton margin: gravity and magnetic interpretation along a traverse across the Wilkes Subglacial Basin region, Earth Planet. Sci. Lett. 192 (2001) 407-421.

[12] P.C. Jones, A.C. Johnson, R.R.B. von Frese, H. Corr, Detecting rift basins in the Evans Ice Stream region of West Antarctica using airbone gravity data, Tectonophysics 347 (2002) 25-41.

[13] Ch. Reigber, R. Bock, Ch. Förste, L. Grunwaldt, N. Jakowski, H. Lûhr, P. Schwintzer, C. Tilgner, CHAMP Phase B-Executive Summary, Sci. Tech. Rep. STR96/13, G.F.Z., Potsdam, 1996, 24 pp.

[14] S. Loyer, S. Bruinsma, D. Tamagnan, J.M. Lemoine, F. Perosanz, R. Biancale, STAR accelerometer contribution to dynamic orbit and gravity field model adjustment, First CHAMP Science Meeting, Potsdam, 2002, pp. 22-25.

[15] N.K. Pavlis, R.H. Rapp, The development of an isostatic gravitational model to degree 360 and its use in global gravity modelling, Geophys. J. Int. 100 (1990) 369-378.
[16] R. Biancale, G. Balmino, J.-M. Lemoine, J.-C. Marty, B. Moynot, A new global Earth's gravity field model from satellite orbit perturbations: GRIM5-S1, Geophys. Res. Lett. 27 (2000) 3611-3614.

[17] R. Rummel, G. Balmino, J. Johannessen, P. Visser, P. Woodworth, Dedicated gravity field missions - principles and aims, J. Geodyn. 33 (2002) 3-20.

[18] L.W. Row, D.A. Hastings, P.K. Dunbar, TerrainBase Worldwide Digital Terrain Data, Documentation Manual, CD-ROM Release 1.0, National Geophysical Data Center Key to Geophysical Records Documentation, No. 30, 1995, 180 pp.

[19] Data Announcement 88-MGG-02, Digital Relief of the Surface of the Earth, NOAA, National Geophysical Data Center, Boulder, CO, 1988.

[20] W.D. Mooney, G. Laske, G. Masters, Crust5.1: a global crustal model at $5 \times 5$ degrees, J. Geophys. Res. 103 (1998) 727-747.

[21] H.-C. Nataf, Y. Ricard, 3SMAC: an a priori tomographic model of the upper mantle based on geophysical modeling, Phys. Earth Planet. Inter. 95 (1996) 101-122.

[22] C. Bassin, G. Laske, G. Masters, The current limits of resolution for surface wave tomography in North America, EOS Trans. AGU 81 (2000) F897.

[23] U.S. Brink, R.I. Hackney, S. Bannister, T.A. Stern, Y. Makovsky, Uplift of the Transantarctic Mountains and the bedrock beneath the East Antarctic ice sheet, J. Geophys. Res. 102 (B12) (1997) 27603-27621.

[24] N.I. Christensen, W.D. Mooney, Seismic velocity structure and composition of the continental crust: a global review, J. Geophys. Res. 100 (1995) 9761-9788.

[25] M. Kuhn, Density modeling for geoid determination, in: M.G. Sideris (Ed.), Gravity, Geoid and Geodynamics 2000, IAG Symposia, 123, Springer-Verlag, Berlin, 2000, pp. $272-276$.

[26] J. Korenaga, W.S. Holbrook, R.S. Detrick, P.B. Kelemen, Gravity anomalies and crustal structure at the southest Greenland margin, J. Geophys. Res. 106 (B5) (2001) 8853-8870.

[27] C.R. Bentley, J.M. Wahr, Satellite gravity and the mass balance of the Antarctic ice sheet, J. Glaciol. 44 (1998) 207-213.

[28] J. Wahr, D. Wingham, C. Bentley, A method of combining ICESat and GRACE satellite data to constrain Antarctic mass balance, J. Geophys. Res. 105 (B7) (2000) 16279-16294. 